GA-A24492

\title{
MANUFACTURING OF MAGNETIC PROBE COILS FOR DIII-D
}

\author{
by \\ A.S. BOZEK and E.J. STRAIT
}




\section{DISCLAIMER}

This report was prepared as an account of work sponsored by an agency of the United States Government. Neither the United States Government nor any agency thereof, nor any of their employees, makes any warranty, express or implied, or assumes any legal liability or responsibility for the accuracy, completeness, or usefulness of any information, apparatus, product, or process disclosed, or represents that its use would not infringe privately owned rights. Reference herein to any specific commercial product, process, or service by trade name, trademark, manufacturer, or otherwise, does not necessarily constitute or imply its endorsement, recommendation, or favoring by the United States Government or any agency thereof. The views and opinions of authors expressed herein do not necessarily state or reflect those of the United States Government or any agency thereof. 


\title{
MANUFACTURING OF MAGNETIC PROBE COILS FOR DIII-D
}

\author{
by \\ A.S. BOZEK and E.J. STRAIT
}

This is a preprint of a paper presented at the 20th IEEE/NPSS Symposium on Fusion Engineering, San Diego, California, October 14-17, 2003 and to be published in Fusion Science and Technology.

\author{
Work supported by \\ the U.S. Department of Energy \\ under Contract No. DE-AC03-99ER54463
}

\section{GENERAL ATOMICS PROJECT 30033 MARCH 2004}




\title{
Manufacturing of Magnetic Probe Coils for DIII-D
}

\author{
A.S. Bozek, E.J. Strait \\ General Atomics, PO Box 85608, San Diego, CA 92186-5608
}

\begin{abstract}
The magnetic diagnostics program at DIII-D adds to its in-vessel installations of induction-type loops and coils almost every year. The current design of toroidal and poloidal magnetic field coils $\left(45-50 \mathrm{kHz}, \mathrm{N} \cdot \mathrm{A}=0.06 \mathrm{~m}^{2}\right)$ has been in existence since 1987. Many coils were installed in DIII-D during that year and are still operating and reliable today. The high reliability of the coils is owing to the use of a continuous length of mineralinsulated cable, eliminating any electrical connections inside the vacuum vessel. The geometry of the probes was designed to achieve a bandwidth of $50 \mathrm{kHz}$, despite the conducting shell formed by the stainless steel sheath of the mineral-insulated cable. The bandwidth is sensitive to the details of the cable dimensions and winding technique, and care must be taken in the fabrication in order to maintain this specification. With possible future magnetic diagnostics installations in ITER and other longpulse machines requiring large numbers of coils and/or multiple layers per coil, the manufacturing scale-up, quality control, and the development of layered coils should all be investigated in addition to the obvious issues such as irradiation effects.
\end{abstract}

\section{INTRODUCTION}

The magnetic coils and loops that have been installed in DIII-D for the past 18 years are based on the common induction loop where a conductor is wrapped into a coil made up of multiple turns. These simple induction coils produce reliable magnetic field and magnetic fluctuation data, and the various loops and coils recently used in the DIII-D tokamak have proven to be robust. Whether the specific coil is designed and positioned within the tokamak to measure the overall plasma current, the localized poloidal and toroidal magnetic fields within the plasma, the current in the tokamak field coils, or high frequency magnetic fluctuation plasma events, the basic principle in all of these coil designs is the same; the voltage induced in the multiple-turn coil by a time-varying magnetic field is integrated to give an output signal proportional to the magnetic field.

\section{COIL EXPERIENCE}

An older-style induction coil design was previously installed in the DIII-D fusion tokamak. It had bare copper wire covered with glass cloth insulation that was wound into a coil on a Macor rod. The coils were placed in a welded metal channel that was mounted in primary vacuum to protect the vacuum from the glass cloth insulation. This welded metal channel, with a rectangular cross-section, contained a reentrant secondary vacuum (Fig. 1). This installation eventually became the largest leak to the primary vacuum due to a leaky seam weld that was continuous along the entire channel, so it was desirable to remove it. Plus, the older-designed magnetic probes, one by one, had been failing over the past 15 years. Unlike their successor whose conductor is continuous and is completely surrounded by an insulator with a seamless sheath, the old-style design had a bare copper conductor in a closelywound coil. Once the conductor left the coil, it was brazed to the center conductor in a coax cable. This braze joint gave way after several years of thermal cycling from high-temperature vacuum vessel baking, which lead to the coil failures. In contrast, the newer design probes described here have never

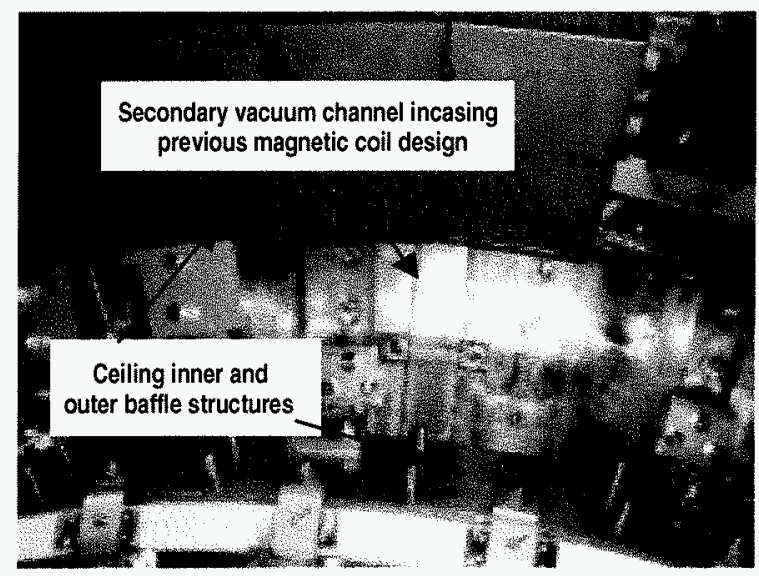

Fig. 1. DIII-D tokamak ceiling with old-style magnetic coil installation.

had a failure of the in-vessel components during use. The only problems experienced have been caused by accidents during installation, or failures of the ex-vessel connectors which are easily repaired.

\section{COIL DEVELOPMENT}

When a new coil design was proposed with continuous coax wire consisting of a seamless stainless steel sheath surrounding a center conductor nickel-clad copper wire separated by magnesium oxide (MgO) compressed powder insulation, a design study was conducted to determine the coil dimensions such that the coil would maintain a bandwidth of at least $50 \mathrm{kHz}$. This is a minimum requirement in order for Ithe coils to measure not only the steady, time-averaged value of the magnetic field, but also high frequency magnetic fluctuations caused by instabilities in the plasma.

The outer sheath of the coax acts as a conducting shell around the center conductor that forms the actual coil winding, and this shell tends to attenuate high frequencies. As discussed below, the cutoff frequency of the shell can be determined from its one-turn inductance and resistance. In practice, it is found that if the $50 \mathrm{kHz}$ bandwidth requirement is met for the coil itself, a resonance between the inductance of the coil winding and the capacitance of the cable can extend the effective bandwidth to about $200 \mathrm{kHz}$ [1].

To design and test the frequency response range, or bandwidth, of the coils, the following formulation is used based on the dimensions of the coil sheath:

$$
f=\frac{1}{2 \pi \frac{\mathrm{L}}{\mathrm{R}}}
$$

The value of $L / R$ is defined as the time constant, $\tau$, of an inductor/resistor circuit [2]. Here $\tau$ represents the time for induced currents in the cable sheath to decay. These currents tend to cancel the magnetic field inside the coil. Therefore, for the tokamak magnetic coils, $\tau$ serves as the cut-off time of 
high frequency magnetic fluctuations such that fluctuations occurring in a time span less than $\tau$ (higher frequency) will be attenuated by the sheath. The inductance of the sheath is calculated using:

$$
\mathrm{L}=\frac{\mu_{0} \mathrm{~N}^{2} \mathrm{~A}_{\text {coil }}}{l_{\text {length,coil }}} \text {, }
$$

where this version of the equation was derived for a solenoid geometry with a vacuum core. Since the outer sheath tubes are in contact, the coils act as one turn, so $\mathrm{N}=1$. $l_{\text {length,coil, is the }}$ length of the wound coil, and $\mathrm{A}_{\text {coil }}$ is the cross-sectional area looking down the center of the coil. $\mu_{0}$ is the magnetic permeability of free space. The sheath resistance is calculated using:

$$
\mathrm{R}=\rho \frac{l_{\text {perimeter }}}{\mathrm{A}_{\text {sheath }}},
$$

where the length, $l_{\text {perimeter }}$ is the perimeter of the coil. The current is perpendicular to the magnetic field, so it travels circumferentially around the coil (Fig. 2). The area, $A_{\text {sheath, is }}$ the cross-section area formed by all the touching coax cable sheaths' tube cross-sectional areas. The electrical resistivity, $\rho$, is for the coax sheath material.

The result of this calculation is very sensitive to the geometry of the overall coil dimensions and the coax sheath dimensions. The coax cable specification calls for $1.57 \mathrm{~mm}$ outer dia. sheath with a wall thickness $0.152 \mathrm{~mm}$ and a tolerance of $-0.000+0.025 \mathrm{~mm}$. The center conductor is a nickel-clad copper wire with $\mathrm{MgO}$ pressed powder as the insulator between the center conductor and the outer sheath. The coax cable that was manufactured for DIII-D in 2002 had a wall thickness on the high end of the specified tolerance, so its wall thickness measured $0.178 \mathrm{~mm}$. Looking at this effect as shown in Table I, if the cable had been delivered on the low side of the material specification, the bandwidth could have possibly been $15 \%$ greater.

When designing the standard-width coil for DIII-D, the width was set at $5.715 \mathrm{~cm}$ so that the coil would fit between the support feet of the graphite armor tiles, which is a typically a $6.350 \mathrm{~cm}$ span. In order to have the desired $50 \mathrm{kHz}$ bandwidth, the height of the coil assembly was varied. Table II

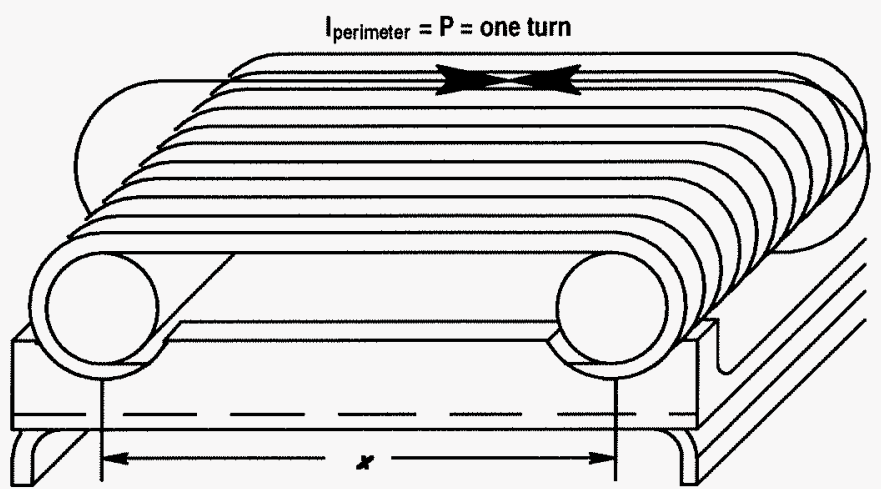

Fig. 2. Rough isometric sketch showing conductor length consideration of a tokamak magnetic coil when evaluating coil resistivity. shows how the height of a wound coil with a $5.715 \mathrm{~cm}$ width affects the bandwidth. The values in Table II show that the greater the coil height, the lesser is its bandwidth range.

TABLE I

BandWidth DEPENDENCE ON SHEATH WaLl THICKNESS

\begin{tabular}{ccc}
\hline $\begin{array}{c}\text { Sheath Wall } \\
\text { WallThickness } \\
(\mathrm{mm})\end{array}$ & $\begin{array}{c}\text { Bandwidth } \\
(\mathrm{Hz})\end{array}$ & $\begin{array}{c}\text { Percent Change } \\
\text { from } \\
\text { Baseline Bandwidth }\end{array}$ \\
\hline 0.152 & 57,400 & $15 \%$ increase \\
.178 baseline design & 50,100 & baseline \\
0.203 & 44,600 & $11 \%$ decrease \\
0.229 & 40,400 & $19 \%$ decrease \\
\hline
\end{tabular}

TABLE II

BandwidTh Dependence on CoIl Cross Sectional AREa

\begin{tabular}{ccc}
\hline $\begin{array}{c}\text { Wound Coil } \\
\text { Height } \\
(\mathrm{mm})\end{array}$ & $\begin{array}{c}\text { Bandwidth } \\
(\mathrm{Hz})\end{array}$ & $\begin{array}{c}\text { Percent Change } \\
\text { from } \\
\text { Baseline }\end{array}$ \\
\hline 12.04 & 52,400 & $5 \%$ increase \\
12.67 baseline design & 50,100 & baseline \\
13.31 & 48,000 & $4 \%$ decrease \\
13.94 & 46,100 & $8 \%$ decrease \\
14.58 & 44,400 & $11 \%$ decrease \\
\hline
\end{tabular}

\section{COIL MANUFACTURING}

In 2002, 25 magnetic coils were manufactured for installation during the upcoming DIII-D in-vessel maintenance period. Twelve of these 25 coils were a revision to the typical $50 \mathrm{kHz}, \mathrm{N} \cdot \mathrm{A}=0.06 \mathrm{~m}^{2}$ coil design. These would be installed in the center of each of 12 internal ("I") control coils to be used for resistive wall mode (RWM) experimentation (see Fig. 3). These magnetic coils are called "double wide" feedback coils because the width of the coil windings' flat sections was doubled. Looking at Fig. 2, the standard-width, 88-turn coils have the flat section " $x$ " dimension equal to $4.445 \mathrm{~cm}$. The "double wide" 97 -turn coils have this dimension equal to $8.890 \mathrm{~cm}$. Also, their $\mathrm{N} \cdot \mathrm{A}$ value was desired to be at least double that of the standard width 88 turn coils.

Most of the remaining 13 manufactured coils replaced existing in-vessel coils that were being removed. Four of the

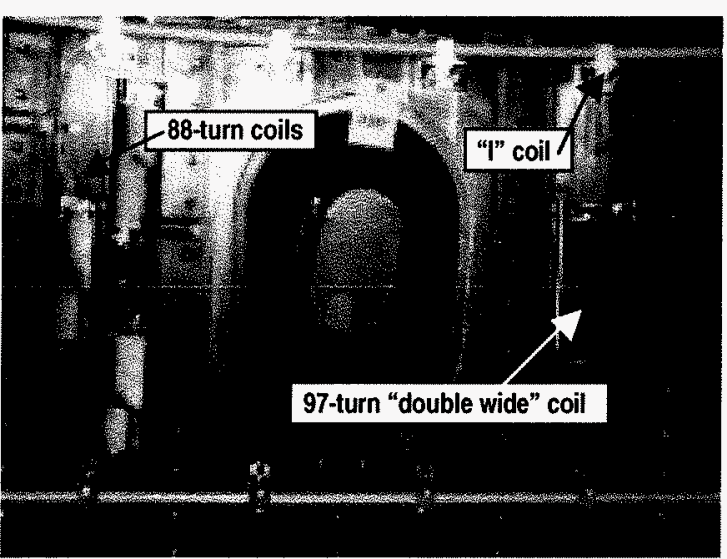

Fig. 3. DIII-D 88-turn magnetic coils, installed for 15 years, and a new 97-turn "double wide" coil. RWM "I" coil horizontal members also in view. 
coils removed from in-vessel had a bandwidth of $35 \mathrm{kHz}$, less than the desired $50 \mathrm{kHz}$. These low bandwidth coils were made to the same design specifications and manufactured the same way as all the other 88-turn coils. So, it is desirable to understand why these coils had a lower bandwidth so that the coils would not be manufactured again with this lower frequency response value.

\section{A. Coil General Manufacturing Procedure}

The coils are wound around two ceramic rods, which are placed in tooling that inserts into a Weldline rotating weld machine. Once the coil is wound, the tooling is removed from the Weldline machine, then the coil is removed from the tooling on the bench, end caps are placed on the ceramic rods, and the coil, ceramic rods, and end caps subassembly is clamped and welded onto an Inconel backplate. A simple side view of the coil assembly is shown in Fig. 4 (end caps not shown for clarity).

During coil winding, the Weldline machine rotation speed is set between 2 and 3 revolutions per minute (rpm). As the tooling is rotated, the coax wire is wound around the two ceramic rods to form an elliptical cross section. The wire is manually guided throughout the winding process. If it were not for the improved clamping fixtures briefly discussed in Section IV.B later in this paper, several manufacturing steps would require two people. The process can now be accomplished by one person, however the steps such as putting the coax wire on the supply spool and twisting the leads after winding the coil are more easily accomplished with two people. The supply spool for the coax wire has a tension device attached. The tension is needed because the coax wire resists the bending around the ceramic rods. Once the coil is wound and removed from the tooling, it is clamped for welding onto the backplate. Prior to welding, the coax wire leads are stripped and the continuity is checked to assure that no shorts have developed between the center conductor and the outer sheath during the coil winding process. Either before or after welding, the coil leads are twisted with approximately one twist per inch. The coil assembly is then baked to anneal the wire, remove surface contamination from the stainless steel sheath, and to outgas the $\mathrm{MgO}$ insulator. The coil assembly is now ready for calibration.

\section{B. Factors Affecting Coil Shape and Performance}

The magnetic coil assemblies are drawn by designed as shown in Fig. 4, with a racetrack-shaped cross-section having straight sides. However, the actual wound cross-sectional

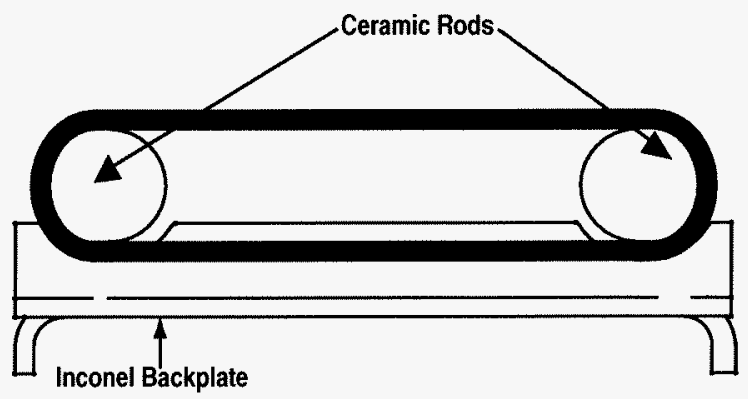

Fig. 4. Side view of magnetic coil showing ideal coax wire racetrack shape, the ceramic rods that the wire is wound onto, and the baseplate. This is referred to here as the baseline design shape. shape is more elliptical, like that shown in Fig. 5. The baseline design height of the coil is $12.67 \mathrm{~mm}$ versus a coil height that was sample measured and averaged for a manufactured coil assembly height of $15.62 \mathrm{~mm}$. This sample measurement was taken off the coils that were previously installed in DIII-D and were removed due to the lower bandwidth range. This rounded shape adds to the cross-sectional area and perimeter of the coil dimensions, affecting the inductance and resistance of the sheath, which changes the bandwidth of the coil. Table III shows the bandwidth differences between the baseline design, shown in Fig. 4, versus that of the more rounded profile shown in Fig. 5.

There is speculation that if the winding process is accelerated (faster than 2 to $3 \mathrm{rpm}$ ), the cross-sectional shape would be worse (more rounded) because the tension device would be applying a load on each turn of the coil for less time. As mentioned earlier in this paper, some coils previously manufactured and installed in DIII-D had a lower bandwidth capability $(35 \mathrm{kHz})$ and were unable to detect the magnetic fluctuations of the slightly higher frequency $(50 \mathrm{kHz})$. The speculation is that these probes were wound at a higher rpm, not applying the tension on each coil turn long enough to flatten it around the ceramic rods.

Another contribution to the lowered bandwidth is that an off-the-shelf coax cable with the same sheath outer diameter of $1.575 \mathrm{~mm}$ but with a $0.0254 \mathrm{~mm}$ greater wall thickness was available. As seen in Table I, the cable with the $0.203 \mathrm{~mm}$ wall thickness has an $11 \%$ decrease in bandwidth over the baseline design. Considering this increased wall thickness effect plus the more rounded shape of the coil windings has a decrease affect on the coil bandwidth. If these are additive effects, the bandwidth reduction would be $10 \%$ plus $11 \%$ for a total of $21 \%$.

To aid in the shaping of the wound coil once it is removed from the winding tooling, clamping fixtures were developed that accomplished two things: (1) it uniformly flattened the wound coil to attempt to form it more like the baseline design and preserve bandwidth range, and (2) previous C-clamping of

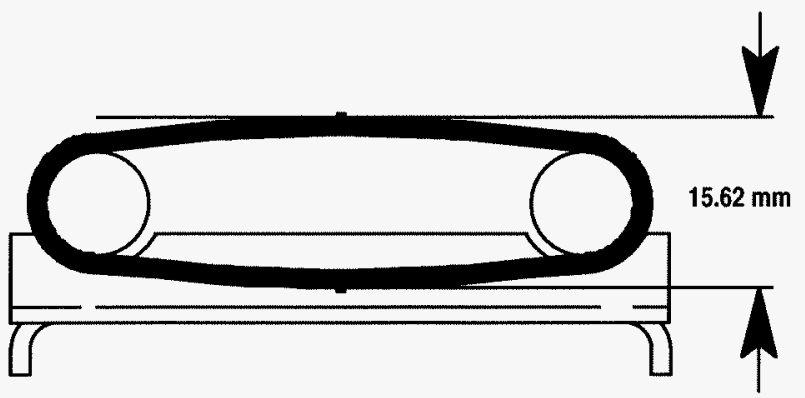

Fig. 5. Side view of magnetic coil showing an average coax wire elliptical shape, taken from optical comparator measurements.

TABLE III

BANDWIDTh DEPENDENCE ON COIL CROSS-Sectional AREA

\begin{tabular}{ccc}
\hline $\begin{array}{c}\text { Wound } \\
\text { Coil } \\
\text { Area } \\
\left(\mathrm{cm}^{2}\right)\end{array}$ & $\begin{array}{c}\text { Pandwidth } \\
(\mathrm{Hz})\end{array}$ & $\begin{array}{c}\text { Percent } \\
\text { Change } \\
\text { from } \\
\text { Baseline }\end{array}$ \\
\hline 6.90 (Fig. 4 baseline) & 50,100 & baseline \\
7.72 (Fig. 5) & 45,100 & $10 \%$ decrease \\
\hline
\end{tabular}


the ceramic rods, their end caps, and the backplate was deforming the backplate prior to welding, so much so that the backplate was almost touching the coil windings. Contact between the backplate and coil would affect the resistivity and inductance of the coil sheath and thus lower the bandwidth. The new clamping fixtures did not put a moment about the ends of the backplate and permanently deflect it, so the backplate remained flat.

\section{FUTURE COIL DEVELOPMENT}

Future installations of magnetic coils, perhaps in DIII-D or in other magnetic fusion devices such as ITER or NSTX, may require a greater number of coils to be manufactured. At the onset of the magnetics program design cycle, the possibility of using or modifying a commercially available automated coil winding machine is advisable. The DIII-D coil calibration data shows that the $\mathrm{N} \cdot \mathrm{A}$ values have a measured range of $4.1 \%$ for the "double wide" probes. Typical ITER magnetics calibrations criteria have a coil-to-coil $N \cdot A$ calibration value of $0.1 \%$. Off-the-shelf automated coil winding machines that offer medium to low volume manufacturing, manual loading, quick tooling change capability, and motion control software are available.

The coil design outlined in this paper is used to detect magnetic fluctuations up to approximately $50 \mathrm{kHz}$, and to even higher frequency with the appropriate external circuitry. High frequency coils are also desirable in a magnetic fusion device to measure magnetic fluctuations with frequencies near $200 \mathrm{kHz}$, and even beyond, where highly localized magnetic fluctuations of a few millimeters in wavelength may be studied near the plasma edge [3]. The magnetic devices used to measure these fluctuations are compact, requiring the conductor to be wound in layers instead of a single layer. Or new technologies could be developed for placing induction coils onto printed circuit boards that are compact and made rugged enough to place near the tokamak plasma first wall and be vacuum-compatible [3].

As higher-energy fusion devices are approved and their operational pulse length is extended or made continuous, irradiation effects will have an impact on the coil materials chosen. Testing has shown that irradiation causes swelling of the $\mathrm{MgO}$ insulation used in the coax wire chosen for the DIII-D tokamak coils and other tokamak magnetic coils [6,7]. Radiation-induced electromotive force (RIEMF) can also be a significant problem for magnetic probe coils, made of mineralinsulated coax, causing an unacceptable drift in the integrated output signal. The proper choice of materials may reduce this problem [6].

\section{ACKNOWLEDGMENT}

This work was performed under the U.S. DOE Contract No. DE-AC03-99ER54463. The efforts of Jim Kulchar and Derek Sundstrom to assist in the development of better manufacturing methods are greatly appreciated. The willingness of the DIII-D technical staff to assist as needed towards the 2002 magnetics installation is also appreciated.

\section{REFERENCES}

[1] E.J. Strait, "Frequency response of metal-clad inductive magnetic field probes," Rev. Sci. Instrum., vol. 67, no. 7, pp. 2538-2540, (1996).

[2] R.A. Serway, Physics for Scientists and Engineers, CBS College Publishing, pp. 605-608 (1983).

[3] H. Takahashi, et al, "Magnetic probe construction using thick-film technology," Rev. Sci. Instrum., vol. 72, no. 8, pp. 3249-3259, (2001).

[4] G. Vayakis, private communication, August 2003.

[5] G. Vayakis and C. Walker, "Magnetic diagnostics for ITER/BPX plasmas," Rev. Sci. Instrum., Vol. 74, p. $2409,(2003)$.

[6] T. Shikama, et al, "Irradiation test of diagnostic components for ITER application in a fission reactor, Japan Materials Testing Reactor," Proc. 19th IAEA Fusion Energy Conf. (Lyon, 2002) IAEA, Vienna, 2003, paper CT/P-11. 